\title{
RECHAZO A LOS REFUGIADOS: POLÍTICAS DE LOS ESTADOS PARA COMBATIR LOS FLUJOS DE REFUGIADOS Y RESPONSABILIDAD DE PROTEGER
}

\author{
David Fernando Santiago Villena Del Carpio** \\ Danielle Annoni***
}

Fecha de recepción: 9 de diciembre de 2015

Fecha de evaluación: 29 de febrero de 2016

Fecha de aprobación: 2 de marzo de 2016

Artículo de investigación

DOI: http://dx.doi.org/10.18359/prole.1969

Forma de citación: Villena, D. \& Annoni, D. (2016). Rechazo a los refugiados: políticas de los Estados para combatir los flujos de refugiados y responsabilidad de proteger. Revista Prolegómenos Derechos y Valores, 19, 38, 43-59. DOI: http://dx.doi.org/10.18359/prole.1969

\section{Resumen}

El propósito del artículo es analizar las políticas que están siendo desarrolladas por los Estados para contener o rechazar los flujos de migrantes que tocan su puerta en busca de refugio. En el intento de encontrar una solución a este problema, se examina la posibilidad de hacer uso de los pilares de la responsabilidad de proteger para que la comunidad internacional sea capaz de concentrarse en aquellas situaciones que originan los flujos de refugiados $y$, de esta manera, parar con las violaciones a los derechos humanos, que los refugiados tengan un retorno seguro y mejorar la calidad de vida de la población afectada, para que ya no esté obligada al éxodo. El método de abordaje es el deductivo, es decir, la aplicación de principios a casos particulares. El artículo muestra cómo las políticas de los Estados están siendo diseñadas para impedir el ingreso de refugiados en sus territorios.

\section{Palabras clave:}

Refugiados, responsabilidad de proteger, comunidad internacional.

\footnotetext{
El presente artículo es resultado del proyecto de investigación "Direito internacional dos refugiados e o Brasil: um estudo dos direitos reconhecidos pelo Brasil aos refugiados e como se dá o acesso à justiça em caso de violação", financiado por el Conselho Nacional de Pesquisa (CNPq)-MCTI/CNPQ/Universal 14/2014.

** Graduado en Derecho por la Universidad Católica San Pablo (Arequipa, Perú), máster en Derecho y Relaciones Internacionales por la Universidad Federal de Santa Catarina (UFSC) (Florianópolis, Brasil). Doctorando en Derecho por la UFSC. Miembro de los Grupos de Estudios "Observatório de Direitos Humanos" y "Núcleo de Pesquisas e Extensão sobre as Organizações Internacionais e a promoção da Paz, dos Direitos Humanos e da Integração Regional, Eirenè". Correo electrónico: fernando.villena@posgrad.ufsc.br

**** Profesora de Derecho Internacional y Derechos Humanos en la Universidad Federal de Paraná (Curitiba, Brasil). Doctora en Derecho Internacional por la Universidad Federal de Santa Catarina (UFSC) (Florianópolis, Brasil). Líder del Grupo de Estudios "Observatório de Direitos Humanos" ligado al Conselho Nacional de Pesquisa (CNPq). Líder del Grupo de Estudios "Direitos Humanos nas Relações Internacionais" ligado al CNPq. Investigadora del proyecto "Direito internacional dos refugiados e o Brasil: um estudo dos direitos reconhecidos pelo Brasil aos refugiados e como se dá o acesso à justiça em caso de violação", financiado por el CNPq-MCTI/CNPq/Universal 14/2014. Responsable de la cátedra Sérgio Vieira de Mello pela UFSC. Correo electrónico: danielle.annoni@ufpr.br
} 


\title{
REJECTION OF REFUGEES: POLICIES OF THE STATES TO COMBAT REFUGEE FLOWS AND RESPONSIBILITY TO PROTECTING
}

\begin{abstract}
Summary
The purpose of the article is to analyze the policies that are being developed by the States to contain or reject the flow of migrants that knock their door in search of refuge. In an attempt to find a solution to this problem, it is being discussed the possibility of making use of the pillars of the responsibility to protecting, so that the international community will be able to focus on those situations which cause the flows of refugees and, in this way, to stop the violations of human rights, to ensure that the refugees can return safe and to improve the quality of life of the affected population so it is no longer bound to the exodus. The method of approach is the deductive one, i.e., the application of principles to particular cases. The article shows how the policies of the States are being designed to prevent the entry of refugees in their territories.
\end{abstract}

\section{Keywords:}

Refugees, responsibility to protecting, international community.

\section{REJEIÇÃO AOS REFUGIADOS: POLÍTICAS DOS ESTADOS PARA COMBATER OS FLUXOS DE REFUGIADOS E RESPONSABILIDADE DE PROTEGER}

\section{Resumo}

O propósito do artigo é analisar as políticas que estão sendo desenvolvidas pelos Estados para conter ou rejeitar os fluxos de migrantes que chegam à sua porta buscando refúgio. Na tentativa de encontrar uma solução para este problema, examina-se a possibilidade de fazer uso dos pilares da responsabilidade de proteger para que a comunidade internacional seja capaz de concentrar-se naquelas situações que originam os fluxos de refugiados e, deste modo, parar com as violações aos direitos humanos, que os refugiados tenham um regresso seguro e melhorar a qualidade de vida da população afetada, para que já não esteja obrigada ao êxodo. $\mathrm{O}$ método de abordagem é o dedutivo, ou seja, a aplicação de princípios a casos particulares. $\mathrm{O}$ artigo mostra como as políticas dos Estados estão sendo desenhadas para impedir o ingresso de refugiados nos seus territórios.

\section{Palavras-chave:}

Refugiados, responsabilidade de proteger, comunidade internacional.

\section{Introducción}

El presente artículo tiene por objetivo analizar las políticas que los Estados, generalmente industrializados, desarrollaron para contener los flujos de inmigrantes que buscan, muchas veces, refugio. Se divide en tres secciones: la primera reflexiona sobre cómo afectaron los atentados terroristas del
11 de septiembre del 2011 en Estados Unidos al derecho de refugiados. La segunda sección estudia los cambios en la legislación interna de algunos países ${ }^{1}$, los cuales recortan derechos $\mathrm{u}$ ofrecen menor protección que la que garantiza

\footnotetext{
Se toma de muestra el caso de Australia, pues fue el que causó mayor impacto a partir del incidente de Tampa, en el 2001.
} 
la Convención sobre el Estatuto de los Refugiados (en adelante la Convención). Por último, se estudia cómo la responsabilidad de proteger (R2P, por su abreviatura en inglés) puede ayudar a la comunidad internacional, no solo a reducir el flujo de migrantes, sino también a mejorar la calidad de vida de la población local.

Para alcanzar el objetivo propuesto se utilizó el método bibliográfico, analizando las informaciones publicadas por organismos internacionales. Así mismo, se indagaron artículos científicos especializados que versaron sobre la problemática de los refugiados y la R2P.

Para comprender el panorama actual de las migraciones es importante entender el contexto en el que fue suscrita la Convención. Las migraciones humanas son antiguas y algunas de ellas suceden por motivos económicos, ambientales o cuestiones de violencia y persecución. Fue recién después de la Segunda Guerra Mundial que la comunidad internacional decidió codificar las situaciones por las que una persona puede ser considerada refugiada. Es así que se firmó en 1951, la Convención, debido a los flujos migratorios ocasionados por la guerra. El aspecto más característico de esta Convención era la limitación temporal y geográfica establecida para determinar quién accedía al estatus de refugiado. De esta forma, el artículo 1 declara lo siguiente:

[...]

b) Que, como resultado de acontecimientos ocurridos antes del $1^{\circ}$ de enero de 1951 y debido a fundados temores de ser perseguida por motivos de raza, religión, nacionalidad, pertenencia a determinado grupo social $u$ opiniones políticas, se encuentre fuera del país de su nacionalidad y no pueda o, a causa de dichos temores, no quiera acogerse a la protección de tal país; o que, careciendo de nacionalidad y hallándose, a consecuencia de tales acontecimientos, fuera del país donde antes tuviera su residencia habitual, no pueda o, a causa de dichos temores, no quiera regresar a él.
Del texto citado se concluye que la protección ofrecida cubría de forma directa a los flujos de refugiados ocasionados por la Segunda Guerra Mundial, en específico a los originados en Europa, tales como judíos o aquellos contrarios a los regímenes comunistas. Esta definición restrictiva fue modificada en 1967 a través del Protocolo Adicional, que indica en su artículo 1:

[...]

§2. A los efectos del presente Protocolo y salvo en lo que respecta a la aplicación del párrafo 3 de este artículo, el término "refugiado" denotará toda persona comprendida en la definición del artículo 1 de la Convención, en la que se darán por omitidas las palabras "como resultado de acontecimientos ocurridos antes del $1^{\circ}$ de enero de 1951 y..." y las palabras "...a consecuencia de tales acontecimientos", que figuran en el párrafo 2 de la sección A del artículo 1.

Se amplió así la definición de refugiado, modificando las restricciones de tiempo y espacio, pues ahora la nacionalidad del migrante es irrelevante para establecer su condición de refugiado. No obstante, después de los ataques terroristas a los Estados Unidos en septiembre de 2001, los países firmantes de la Convención comenzaron a criticar el régimen de los refugiados. A partir de esa fecha, los asilados son vistos como una amenaza a la seguridad nacional, pues muchos de ellos fueron catalogados como terroristas.

Debido a que las cortapisas para acceder a la condición de refugiado se incrementaron, muchos refugiados entraron en contacto con grupos criminales que ofrecían un modo de ingresar al Estado de destino. En consecuencia, los refugiados fueron señalados de criminales, aumentando el número de restricciones y detenciones por parte de los países de llegada.

Por lo anterior, el objetivo del presente trabajo es analizar la situación actual de los refugiados, cuáles son las medidas adoptadas por los Gobiernos para manejar los flujos migratorios y una 
posible respuesta por parte de la comunidad internacional a través de la R2P.

\section{A. Desde los ataques de 2001 hasta la actualidad}

Como resultado de los ataques terroristas a los Estados Unidos, muchos Estados adoptaron políticas cuyo objetivo es parar los flujos de migrantes (en este caso posibles refugiados), políticas encajadas dentro de la guerra al terror (Clark y Simeon, 2014) declarada por el bloque occidental; "los refugiados pasaron de ser una categoría de personas protegidas al final de la Segunda Guerra Mundial a ser discriminados dentro del contexto de la migración internacional irregular" (Kneebone, 2009, p. 5). Así, si en los primeros años después de finalizada la Segunda Guerra Mundial se daba prioridad al reasentamiento de los refugiados en los países de destino, ahora se prefiere la repatriación, pues constituye una solución duradera (Kneebone, 2009).

Hay tres dificultades a las que se enfrentan los refugiados una vez salen de su nación: (i) el cierre de fronteras por parte de los países de destino (ONU, 2004); (ii) aumenta la intolerancia, la xenofobia y las agresiones o tensiones étnicas contra los solicitantes de refugio (ONU, 2004) y (iii) las violaciones a los derechos humanos en sus países de origen continúan sucediendo (ONU, 2004).

Es importante resaltar que los Estados de destino deben cumplir con dos principios fundamentales en cuanto a la protección de los refugiados: nonrefoulement, por el cual los refugiados no pueden ser devueltos al lugar donde están sufriendo persecución; y la no discriminación al momento de ofrecer protección a estos. Sin embargo, en el documento Measuring protection by numbers, se indica "que en el 2005, incidencias sobre la devolución de refugiados fueron reportadas por cerca del 50 \% de las oficinas del Alto Comisionado de las Naciones Unidas para los Refugiados (Acnur)" (Acnur, 2006b, p. 1).
Así mismo, existen causas reales de preocupación "cuando una opinión en el Washington Post habló sobre la necesidad de prevenir los flujos fronterizos de 'personas peligrosas', las cuales fueron calificadas como integrantes de milicias, invasores extranjeros, terroristas y refugiados" (Acnur, 2006b, p. 3).

Estas críticas no solo vienen de instituciones privadas, sino también de los propios países que firmaron la Convención. En este sentido, si durante la Guerra Fría era más fácil aceptar refugiados que tenían una cultura semejante a la del país de destino y satisfacían la necesidad de mano de obra, ahora la situación mudó, ya que, como indica el Acnur

[...] tras el fin de la Guerra Fría, muchos países pasaron a considerar a los refugiados más como una carga que como una ventaja. Además, desde los atentados del 11 de septiembre de 2001 en los Estados Unidos, la preocupación por la seguridad del Estado ha llegado a dominar el debate sobre las migraciones, eclipsando en ocasiones las necesidades legítimas de protección que tienen los individuos (2006a, p. 1).

En este sentido, los Gobiernos consideran la institución del refugio como una puerta abierta que permite el ingreso de inmigrantes, constituyendo una amenaza a la seguridad nacional. Es así que dos tendencias negativas han surgido. La primera

[...] es una aplicación excesivamente restrictiva de la Convención y su Protocolo de 1967, lo que ha dado lugar a un incremento de las detenciones y las exclusiones [...] La segunda es una proliferación de mecanismos alternativos de protección que garantizan menos derechos que los de la Convención (Acnur, 2006a, p. 2).

Estos mecanismos tienden a transferir a los refugiados a terceros países de destino. Debido a estas tendencias negativas, los posibles Estados de destino ahora miran a las víctimas como si fueran criminales y no centran su atención en 
las causas que producen el fenómeno de la inmigración forzada.

Un caso emblemático del trato que están recibiendo los refugiados en los países desarrollados es el de Tampa. El navío Tampa, de bandera noruega, rescató a 438 afganos de aguas indonesias, llevándolos a aguas territoriales australianas. Sin embargo, el Gobierno australiano negó el pedido de refugio, manifestando que esos afganos constituían un peligro para el país (Dauvergne, 2008). No obstante, hasta ese momento se había aceptado el pedido de refugio del $85 \%$ de afganos que ahora se consideraban migrantes ilegales.

Para librarse de esta situación incómoda, el Gobierno australiano firmó la llamada "Solución Pacífica", por la cual Australia entraba en acuerdos con Nueva Zelandia, Papúa Nueva Guinea y Nauru para que aceptaran estos refugiados. A cambio, "estos acuerdos ofrecieron una fuerte suma de dinero a Papúa Nueva Guinea y Nauru, los cuales no habían establecido un sistema para atender los pedidos de refugio" (Dauvergne, 2008, p. 52).

A pesar de que Australia representa un pequeño porcentaje en cuanto a recepción de refugiados, influyó para que otras naciones adoptaran medidas similares. Australia modificó sus procedimientos legales, excluyendo algunas de sus islas de la jurisdicción del derecho de refugiados. De esta forma, aquellas islas que eran de fácil acceso para los refugiados tenían el estatus de lugares de ultramar. Es así que, "los migrantes que llegaban a estas islas no podían pedir visas como lo haría cualquier otro refugiado" (James, 2014, p. 209).

Así mismo, los Estados Unidos incrementaron su presupuesto para el control de fronteras, pasando de 1700 millones de dólares en 2005 a 3600 millones de dólares en 2010. Entre otras medidas de seguridad, la administración norteamericana tomó fotos de 113 millones de personas que cruzaron la frontera entre 2004 y 2008 (James, 2014). Ya el Reino Unido propu- so analizar los pedidos de refugio fuera de su territorio (Dauvergne, 2008).

Por otro lado, las leyes canadienses son más rígidas para aquellos individuos que ingresan al país ayudados por traficantes de personas (como los coyotes en la frontera México-Estados Unidos). Igualmente, restringieron el derecho de apelación en varias áreas de su jurisdicción (Dauvergne, 2008). De esta manera, debido al "incremento de la legislación estatal, la cual hace más difícil el cruce de fronteras de determinadas personas, el número de aquellos, definidos técnicamente como refugiados, cayó en un tercio" (James, 2014, p. 215). Aunque esta caída en la cifra de solicitantes de refugio no significa una mejoría en sus condiciones de vida, por el contrario, provoca el aumento de desplazados internos.

En el caso de Australia, este Estado se desvió del espíritu de la Convención. Primero, su reticencia a recibir a posibles refugiados, en este caso, población afgana que se negaba a ingresar a Indonesia. Segundo, la exclusión de parte de su territorio para efectos del derecho de refugiados como si este territorio no estuviese sujeto a su soberanía. Por último, una delimitación de la población que puede ser considerada perseguida, en este caso, de la población afgana por, supuestamente, representar una amenaza a la nación (Dauvergne, 2008).

Como consecuencia del caso Tampa, en 2002 la Organización Marítima Internacional adoptó una resolución en cuanto al tratamiento de personas rescatadas en ultramar. De esa forma, "el gobierno responsable por la seguridad marítima y rescate en la zona de seguridad y rescate donde los sobrevivientes fueron salvados es responsable por encontrar un lugar seguro para ellos" (Clark y Simeon, 2014, p. 17).

Otro problema presente es que algunos países (por ejemplo Turquía) permanecen en las antiguas definiciones geográficas de origen de los refugiados, por lo cual solo aceptan a aquellos venidos de países europeos (Alborzi, 2006). Es 
decir, en el caso actual de sirios que huyen de la violencia ocasionada por el Islamic State of Iraq and Syria ${ }^{2}$ (Isis) o de la violencia generada por la guerra civil que comenzó en el 2012, ellos no encontrarían refugio en Turquía (siendo este país vecino y natural destino de refugiados sirios), pues no provienen de ninguna nación europea.

Como anotó Kelley en 2007, las naciones industrializadas desarrollan políticas rigurosas contra el ingreso de migrantes como restricciones de visas y penalización por el uso de documentos falsos; interceptación en puertos extranjeros; interceptación en el mar; negativa de acceso para pedir refugio; declarando que el país de origen de los solicitantes de refugio es seguro; plazos de presentación de documentación más cortos; derechos de apelación limitados; acuerdos de readmisión; detención y trabas para acceder a empleo o servicios sociales.

Sin embargo, las democracias liberales hacen distinciones entre los propios refugiados, pues son receptivas a aquellos refugiados que benefician el mercado o contribuyen al interés nacional (James, 2014). En este sentido, son bienvenidos quienes cuenten con formación superior o portadores de capital capaces de invertir en el desarrollo del país, excluyendo, de esta forma, personas que representan mano de obra barata y cuyo aporte no es significativo a la economía nacional.

2 Este grupo terrorista también es conocido como "Islamic State of Iraq and the Levant" (ISIL) o simplemente como "Estado Islámico". El objetivo del Isis es el establecimiento de un califato moderno (de ahí viene su nombre de "Estado") consistente en un sistema político en el cual, tanto la vida pública como la vida privada, estarán sujetas a una única interpretación de la sharia, convirtiéndose así en derecho estatal (Saltman y Winter, 2014).

3 Debido a las trabas encontradas por los migrantes, una de las rutas para entrar ilegalmente a Europa es por la vía marítima, en este caso zarpando desde Libia hasta llegar a la isla italiana de Lampedusa. Esta travesía es riesgosa, por lo que varios naufragios se han reportado. La tragedia más llamativa ocurrió el 19 de abril del 2015, donde más de 700 inmigrantes murieron ahogados antes de alcanzar las costas de Lampedusa. Según estimaciones del Acnur, en lo que va del presente año, más de 1600 personas han muerto y en el año 2014 esta cifra fue de 3500 muertos (Acnur, 2015).
Esta distinción entre aquellos que aportan al mercado y los que no, genera diferencias en relación con el trato dado por el Estado. Así, se puede hablar de ciudadanos y los otros. A los ciudadanos les está permitido cruzar las fronteras y cuentan con la tutela del Estado. En esta categoría también se encuentran los migrantes documentados y los turistas (James, 2014). Los otros son personas que ingresaron de forma irregular al país o cuyo plazo de permanencia expiró o fueron afectadas por cambios en la legislación sobre residencia (James, 2014).

Aunque "prevenir la migración ilegal es casi imposible y para acercarse cada vez más al total control de las fronteras pueden ser necesarias actividades draconianas difíciles de contemplar para cualquier Estado liberal" (Dauvergne, 2008, p. 157). Así mismo, la citada autora menciona que para algunos doctrinadores el control de la migración por parte de los Estados es una tarea imposible debido al gran avance de los derechos humanos (Dauvergne, 2008).

No obstante, no todo el panorama es gris. En 2013, trece países ${ }^{4}$ firmaron la Declaración de Yakarta sobre el movimiento irregular de personas. Esta declaración visa la protección de personas que fueron traficadas o que ingresaron de modo irregular a cualquier Estado parte. También hubo nuevas adhesiones a la Convención de Refugiados, como es el caso de Nauru en el 2011.

Por otro lado, el Acnur promovió varias reuniones conocidas como Convención Plus, que tenía como objetivo aumentar el compromiso de los Estados donantes para con los Estados de destino, de preferencia aquellos que pertenecen a la región del Estado de origen de los refugiados, así como buscar soluciones duraderas (Betts, Loescher y Milner, 2012). El propósito de la Convención Plus era "enfocar la energía y recursos financieros adicionales sobre el problema de proteger a los refugiados en los flujos migratorios mixtos,

4 Afganistán, Australia, Bangladés, Camboya, Indonesia, Malasia, Birmania, Nueva Zelandia, Pakistán, Papúa Nueva Guinea, Filipinas, Sri Lanka y Tailandia. 
visando el reparto de responsabilidades así como la búsqueda de soluciones duraderas" (Clark y Simeon, 2014, p. 20). No obstante, dicha Convención fracasó debido en parte a la polarización entre los países del norte global (industrializados) y los del sur global (que albergan la mayor cantidad de refugiados en el mundo) (Betts et al., 2012). Así mismo, dificultades presupuestarias dentro del Acnur provocaron que la Convención Plus desapareciera sin haber alcanzado los resultados deseados (Clark y Simeon, 2014).

Otro problema presente en el régimen de los refugiados es que los agentes del Estado de destino tienen dudas al momento de determinar el estatus de aquellos solicitantes de refugio, pues la Convención y el Protocolo no responden al panorama actual. Es por ello que se hace necesaria una nueva recapitulación sobre quién es refugiado, lo que se verá a continuación.

\section{B. Cambios en el derecho de los refugiados}

Cuando se tiene que definir el estatus de refugiado, muchas veces los órganos decisores tienen que hacer juicios de valor subjetivos para decidir qué situaciones pueden ser consideradas como persecución. Además, esta persecución tiene que provocar un temor razonable en el solicitante de refugio para no querer volver o no aceptar la protección de su Estado de origen. Estas incógnitas surgen debido a que, cuando se redactó la Convención y, posteriormente, el Protocolo, se entendía por refugiado al perseguido político que no simpatizaba con las políticas del Gobierno de turno, pues se deseaba atraer a aquellos que huían del este europeo (Alborzi, 2006).

Pese a ello, con el pasar de los años, a excepción de la Convención de la Unidad Africana (OUA) en $1969^{5}$, la definición de refugiado no ha mu-

\footnotetext{
5 La referida Convención amplía el término refugiado "a toda persona que, a causa de una agresión exterior, una ocupación o una dominación extranjera, o de acontecimientos que perturben gravemente el orden público en una parte o en la totalidad de su país de origen, o
}

dado. Es así que ya no se habla de refugiados políticos del este europeo como el principal grupo que solicita refugio, sino de flujos de personas que emigran por razones menos políticas y más humanitarias. Debido a que los solicitantes de refugio traspasan de forma masiva las fronteras, a diferencia de los refugiados políticos cuyo movimiento era individual, el Estado de destino se encuentra imposibilitado de prestarles correcta atención o socorro. De modo que muchos "Estados se han encontrado en situaciones dramáticas, enfrentando a cientos de miles de refugiados sin abrigo, comida, facilidades sanitarias o seguridad" (Alborzi, 2006, p. 174).

La Convención tampoco establece los procedimientos para que los Estados lidien con flujos masivos de refugiados. Un caso aparte lo constituye el éxodo húngaro de 1956, en el cual el Acnur dejó de lado la determinación individual de refugiado y reconoció como tal a todo húngaro que quisiese salir del país (Alborzi, 2006). Esta preocupación fue plasmada por Millbank (2000), para quien el problema de la Convención y el Protocolo es que no ofrecen protección a los refugiados hasta que alcancen un Estado parte; no existe mecanismo que garantice un retorno seguro al país de origen; no hay un método para prevenir los flujos masivos de migrantes y no se tiene en cuenta la capacidad de recepción del Estado de destino.

Por estos problemas, muchos países industrializados cuestionan las obligaciones impuestas tanto por la Convención como por el Protocolo, recurriendo a políticas como la repatriación o la denegación del pedido de refugio. Como explica Hathaway (1998), la dificultad radica en que se coloca toda la carga en aquellas naciones que sirven de destino para los migrantes.

del país de su nacionalidad, está obligada a abandonar su residencia habitual para buscar refugio en otro lugar fuera de su país de origen o del país de su nacionalidad". Véase Convención de la OUA por la que se regulan los aspectos específicos de problemas de los refugiados en África. 
Dentro de estas políticas agresivas contra los refugiados, existe una que está cobrando fuerza: tercer país seguro, cuyo caso más destacado es el de Tampa descrito líneas arriba. Esta política emergió cuando un gran número de solicitantes de refugio se encontraba en Europa y el sistema europeo de refugio podía colapsar. A través de esta política un Estado puede enviar a los solicitantes de refugio a otro país, con el cual haya celebrado acuerdos en la materia y garantice que el solicitante hallará refugio y recibirá protección de acuerdo con la Convención de 1951 (Kneebone, 2009).

Además, en el tercer país de destino no debe haber riesgo de persecución, refoulement o cualquier otra violación al derecho de los refugiados. Sin embargo, Australia, tal como fue visto en el incidente de Tampa, envió a los solicitantes de asilo a naciones que presentaban bajos índices de protección efectiva de los refugiados (Kneebone, 2014). No obstante, la Corte Suprema de Australia manifestó que el país no podía librarse de sus obligaciones para con los refugiados, a no ser que estos sean enviados a otro Estado que ofrezca la misma calidad de protección garantizada en las leyes australianas (Kneebone, 2014).

Por ello el Parlamento australiano decidió modificar la ley de inmigración. Gracias a esta modificación, el tercer país seguro no necesitaba cumplir todas las obligaciones establecidas en la Convención. De este modo, Australia legitimó lo que puede ser descrito como un régimen de responsabilidad mutable en vez de un régimen de responsabilidades compartidas (Foster, 2012), lo cual no deja de ser una afrenta a la Convención, pues coloca en riesgo la vida de los solicitantes de refugio.

Se están produciendo entonces cambios en relación con las políticas migratorias: primero, el control de fronteras es más rígido que antes. Segundo, el problema de los refugiados está perdiendo su connotación humana para ser tratado como un problema político. Por último, el procedimiento legal sobre los solicitantes de refugio es más complejo, abriendo paso a legislaciones xenófobas (James, 2014). Tal es el caso de la ley de Arizona SB1070, la cual consideraba criminales a todos aquellos que parecían ser inmigrantes, sean documentados o no. En este sentido, "una forma de lograr el control es limitar el alcance de que los derechos de los refugiados sean percibidos como derechos humanos" (Dauvergne, 2008, p. 63). Es decir, se trata de que los refugiados sean vistos como una amenaza para el Estado de destino y, en el ámbito interno, como una carga económica a ser soportada por los contribuyentes.

A pesar de las críticas suscitadas por los países de destino, el derecho de refugiados es importante para los Estados. Según Hathaway el derecho de refugiados "parte de la necesidad de los Estados de comprometerse a encontrar respuestas adecuadas al arribo masivo de inmigrantes, así como a diseñar sus valores legales y políticos" (2007, p. 99). Además, el derecho de refugiados da a los Estados un amplio margen para maximizar el control de sus fronteras (Hathaway, 1990).

La formulación de respuestas y de los valores legales y políticos dará paso a la construcción de políticas destinadas a dar cabida a los flujos de inmigrantes de forma conjunta y coordinada con otros países o con la comunidad internacional, ya que afrontar el esfuerzo en solitario puede representar demasiada carga para el Estado de destino. Es por ello que la formulación de estas políticas exige que los Estados actúen de manera justa y equitativa, es decir, a través de un sistema organizado y coherente que evite las arbitrariedades.

El primer paso para ofrecer un mejor trato a los refugiados es dar respuesta a situaciones complejas que requieren de la observación atenta por parte de los agentes del Estado encargados de atender los pedidos de refugio. Para descubrir estas respuestas se desarrollaron dos modelos para determinar el nivel de persecución sufrido.

El primer modelo corresponde al de Jean-Yves Carlier, el cual consiste en una pregunta central: ¿existe riesgo de persecución si el solicitante de 
refugio retorna a su país de origen? Que se subdivide en tres interrogantes específicos: ¿̇hasta qué punto hay riesgo de persecución? ¿Hasta dónde se puede hablar de persecución? Y ¿hasta qué punto el riesgo de persecución está establecido? (Carlier, Vanheule, Peña y Hullman, 1997).

La importancia de este modelo radica en que sin una guía para tomar las decisiones, el pedido de los refugiados se deja al arbitrio de los órganos decisores, quienes pueden ser movidos por opiniones ya formadas o apreciaciones subjetivas. En este sentido

[...] mientras más fundamental el derecho sea (a la vida, integridad física, libertad...) menos cuantitativa y cualitativa será la evaluación. Mientras el derecho tenga menos prioridad (derechos económicos, sociales o culturales), la evaluación será más cuantitativa y cualitativa (Carlier et al., 1997, p. 703).

Este modelo coloca énfasis en la escala o jerarquía de derechos amenazados, donde los derechos civiles y políticos tienen más peso que los sociales, económicos o culturales. Esta jerarquía serviría de base para que el agente del Estado de destino pueda decidir en relación con el pedido de refugio. Si bien la crítica hecha a este modelo es que no establece cómo reaccionar frente a situaciones que articulan, en diverso grado, los derechos envueltos, además que en los pedidos de refugio no se presenta de forma clara cuál es el derecho amenazado; o cómo dar mayor importancia a un derecho que no sea fundamental.

El segundo modelo fue ideado por James Hathaway y se apoya en la Carta Internacional de Derechos Humanos, la cual comprende la Declaración Universal de Derechos Humanos (DUDH), el Pacto Internacional de Derechos Civiles y Políticos (ICCPR, por su sigla en inglés) y el Pacto Internacional de Derechos Económicos, Sociales y Culturales (ICESCR, por su sigla en inglés). El modelo de Hathaway tiene bastante aceptación debido a que los estándares aplicados son admitidos por los Estados partes de los tratados que ya nombramos, por lo que no es necesario introducir nuevos parámetros.
Hathaway (1991) define persecución como un incumplimiento sistemático o reiterado por parte del Estado en relación con uno de los derechos fundamentales. Con base en esta definición, su modelo consiste en cuatro categorías que explicarían en qué circunstancias existe persecución. En la primera categoría están los derechos recogidos en la DUDH y que también se encuentran en el ICCPR (Hathaway, 1991). Esta lista de derechos incluye el derecho a la vida; prohibición de tortura o cualquier castigo humillante e inhumano; prohibición de esclavitud, irretroactividad de la ley penal; libertad de pensamiento, conciencia y religión; y prohibición de ser encarcelado por deudas. La naturaleza inderogable, aún en Estados de emergencia, de estos derechos los eleva por encima de cualquier otro y la supresión de los mismos constituye un serio riesgo de persecución.

La segunda categoría se conforma por aquellos derechos que solo pueden ser derogados en situaciones de emergencia pública. Se incluyen: prohibición de detención o arresto arbitrario; derecho a la protección igualitaria, incluyendo niños y minorías; derecho a un debido proceso y presunción de inocencia hasta que se pruebe lo contrario; protección a la privacidad e integridad familiar; libertad de movimiento; libertad de opinión, expresión y asociación; derecho de participar en el Gobierno; derecho al trabajo sin discriminación; y derecho a elecciones justas y periódicas (Hathaway, 1991).

El Gobierno solamente podrá prohibir el ejercicio libre de estos derechos cuando sea declarado el Estado de emergencia en todo o parte de su territorio. En caso de que no se haya declarado dicho Estado de emergencia o este no haya cumplido con los procedimientos legales, se estará frente a una situación de persecución.

La tercera categoría contiene aquellos derechos inscritos en la DUDH ${ }^{6}$ y en el ICESCR. La diferencia entre el ICCPR y el ICESCR está en que este último "no impone un estándar de

6 Ratificada el 16 de diciembre de 1949 por la Asamblea General de la ONU. 
cumplimiento, sino que pide a los Estados tomar todas las medidas posibles para el progresivo cumplimiento de estos derechos sin discriminación alguna" (Hathaway, 1991, p. 110). Algunos de los derechos comprendidos en esta categoría son: el derecho al trabajo; derecho a comida, casa, vivienda, atención médica y educación básica; así como beneficiarse de las expresiones científicas, literarias, culturales y artísticas (Hathaway, 1991). En este caso, si el Estado posee los recursos materiales y económicos para garantizarlos pero no los hace efectivos o, peor aún, discrimina a la población que pueda favorecerse de ellos, también estaremos ante un riesgo de persecución.

La cuarta categoría comprende aquellos derechos contenidos en la DUDH pero que no están presentes en el ICCPR o ICESCR. Se trata del derecho de propiedad y el de gozar de protección frente al desempleo. La característica de estos derechos es que su incumplimiento "no es motivo suficiente para servir de base al reclamo de falta de protección estatal debido a que no están sujetos a una obligación legal vinculante" (Hathaway, 1991, p. 111). Por lo tanto, no servirían de cimiento para un pedido de refugio, ya que su incumplimiento no responde a un elemento de persecución por parte del Estado.

La diferencia entre el modelo de Carlier y el modelo de Hathaway es que este coloca énfasis en la obligación de proteger los derechos por parte del Estado, mientras que aquel implica la diferencia en la prioridad normativa entre las distintas categorías.

El modelo de Hathaway ha sido acoplado en las legislaciones de Canadá, Reino Unido y Nueva Zelandia. En el caso del Reino Unido, este modelo fue reconocido en la jurisprudencia por el Tribunal de Inmigración y Asilo (Foster, 2007). Por otra parte, Australia aún no acoge abiertamente el modelo de Hathaway, pero los agentes que toman la decisión respecto al pedido de refugio muestran voluntad de considerar la existencia de una jerarquía de derechos al momento de determinar el estatus del refugiado (Foster, 2007).
Es importante subrayar que el derecho de refugiados no obliga a los Estados de destino a continuar ofreciendo protección cuando la situación en el país de origen se ha normalizado. En este sentido, la Convención establece seis causales por las cuales se pierde la condición de refugiado: cuando se pide voluntariamente la protección del país del cual tiene nacionalidad; si se recobró la nacionalidad que había perdido; si se adquirió una nueva nacionalidad y disfruta de la protección de este país; si, de forma voluntaria, se asentó en el país de su nacionalidad del cual tenía temor de persecución; si desaparecieron las circunstancias que lo obligaron a huir; y si siendo apátrida, desaparecieron las circunstancias de persecución y es capaz de asentarse nuevamente en el país donde tenía su residencia habitual ${ }^{7}$.

Cuando el Estado de origen está en la capacidad de proteger a sus ciudadanos, el refugiado debería retornar a su país. En el Proceso de Bali ${ }^{8}$ se reforzó la idea de que aquellas "personas que no necesitan protección deberían retornar, de preferencia voluntariamente, a sus países de origen" (Co-Chair's Statement, 2011, p. 3).

La mejor manera de evitar los flujos de migrantes es la prevención de aquellas causas que obligan a la gente a huir de sus hogares. La prevención se inserta en el marco de la R2P, como ayuda ofrecida por la comunidad internacional y es esta la que estudiaremos a continuación.

\section{La responsabilidad de proteger y el derecho de refugiados}

Una solución para hacer frente a los flujos masivos de inmigrantes sería combatir las causas

\footnotetext{
Artículo 1 (c) de la Convención sobre el Estatuto de los Refugiados de 1951.

8 El Proceso de Bali es un foro internacional establecido en 2002 que trata sobre dar respuestas al tráfico de personas y la inmigración indocumentada. Es copresidido por Australia e Indonesia, participando los países de la región de Oceanía y Asia. El Proceso de Bali responde más a los intereses australianos, quien utiliza los incentivos de la ayuda externa y construcción de capacidad, para que se acepten los acuerdos que propone (Kneebone, 2014).
} 
que originan estos flujos: que la comunidad internacional actúe de forma preventiva en los Estados de origen, garantizando el respeto a los derechos humanos. En este sentido, la comunidad internacional puede actuar según los pilares de la R2P.

La R2P cuenta con tres pilares aprobados por la Organización de las Naciones Unidas (ONU) (2009): (i) el Estado tiene la R2P a su población; (ii) la comunidad internacional debe ayudar a los Estados para que cumplan esta responsabilidad y (iii) en caso de que el Estado no pueda o no quiera proteger su población es la comunidad internacional quien debe asumir este compromiso.

El Acnur es una institución de alcance global capaz de actuar en favor de los intereses de individuos o grupos de personas, por lo que se dice que "es una concreta manifestación de lo que el concepto de R2P encierra" (Türk, 2013, p. 40). Esta afirmación se soporta en el trabajo en conjunto que realiza la comunidad internacional (a través del Acnur) para dar respuesta a las necesidades de los refugiados.

Por otro lado, no es menester reformular la Convención ni firmar un nuevo protocolo para implementar la R2P en el derecho de refugiados, ya que es la misma Convención la que presupone la cooperación entre todos los Estados miembros y el Acnur para el ejercicio de sus funciones ${ }^{9}$. De esta forma, la comunidad internacional actuaría conforme con el segundo pilar de la R2P, esto es, cooperando con el Estado de origen para que ofrezca protección a su población, que es la principal causa por la cual las personas buscan refugio en otros países. Si bien la ayuda no deberá dirigirse únicamente al Gobierno para que combata las causas que motivan la migración, porque puede darse que sea el propio Gobierno quien ejecute política cuyo objetivo es el desplazamiento de un sector de la población. Estas políticas son conocidas como régimen de desplazamiento inducido (RID, por su sigla en inglés).

9 Artículo 35 (1) de la Convención sobre el Estatuto de los Refugiados.
El RID "ocurre cuando el gobierno o agentes auspiciados por el gobierno hacen uso de tácticas coercitivas para causar, directa o indirectamente, que grandes números de ciudadanos huyan de sus hogares" (Orchard, 2010, p. 43). También sucede que el desplazamiento constituye una estrategia para consolidar el control sobre determinado territorio (Zaum, 2011). Estos actos pueden ir desde la supresión en el suministro de algún servicio básico, medidas dirigidas a debilitar la economía de la región o la ejecución de crímenes contra la humanidad, limpieza étnica o genocidio. En este último caso, es el Consejo de Seguridad de las Naciones Unidas (CSNU) quien tiene la potestad de tomar las medidas necesarias sobre la base de que aquella situación representa una amenaza a la paz y seguridad internacionales. Así, el CSNU actuaría según el tercer pilar de la R2P, pues es el propio Estado quien no tiene la capacidad, o voluntad, para proteger su población.

Aunque la intervención extranjera para la protección de los derechos humanos de la población sin el consentimiento del Estado receptor es controvertida, no es ajena a la realidad. Un ejemplo de protección en el país de origen ocurrió en la intervención humanitaria en el norte de Irak en favor de los kurdos que se habían desplazado hacia las montañas o a Irán (Alborzi, 2006). También está el caso libio del 2011, constituyendo un nuevo paradigma dentro de la comunidad internacional, pues fue la primera vez que la R2P fue invocada para proteger a la población libia de los ataques del ejército liderado, por ese entonces, por Muamar Gaddafi. Esta intervención consiguió parar con las violaciones a los derechos humanos practicadas por las fuerzas de Gaddafi.

Estos datos muestran que el uso de la fuerza no significaría la introducción de una nueva variable en el campo de las relaciones internacionales, dado que "en los últimos veinte años, la comunidad internacional ha sido más proclive a usar la fuerza militar para parar o prevenir las atrocidades en masa" (Wester y Goldstein, 2011). Esta postura se refleja en las intervenciones humanitarias realizadas en Irak, Kosovo o Libia. 
Uno de los elementos clave de la R2P es el sistema de alerta rápida ${ }^{10}$, el cual fue propuesto cuando, entre 1987 y 1991 el secretario general de la ONU creó el Gabinete de Investigación y Recojo de Información (Office for Research and the Collection of Information, en inglés). Este gabinete tenía como funciones

[...] la realización de actividades de alerta rápida destinadas a prevenir nuevos flujos masivos de refugiados, a controlar factores relacionados a posibles flujos de refugiados $y$ de personas desplazadas y en situaciones de emergencia iguales, y a elaborar proyectos de posibles respuestas (ONU, 2004, p. 20).

La prevención, en este caso, debe centrarse en la causa principal de los problemas, es decir, aquellos factores económicos y políticos que obligan a las personas a huir de su país. Estos factores generalmente son los conflictos internos y externos, las violaciones a los derechos humanos producidas por cualquier agente y el nivel de desarrollo económico.

En este contexto, es válido preguntarse por qué la comunidad internacional debería ayudar en las labores de prevención de conflictos internos si aún no existen flujos de migrantes que amenacen con su estabilidad.

Tal como indica la Declaración de Tlatelolco, firmada en México, las causas que dan origen al flujo de refugiados pueden ser "la persecución, la violación de los derechos humanos, los conflictos armados internos e internacionales y las violaciones al derecho internacional humanitario" (Declaración de Tlatelolco sobre acciones prácticas en el derecho de los refugiados en América Latina y el Caribe, 1999). Así mismo lo expresó la Comisión de los Derechos Humanos, la cual "resaltó la relación existente entre las violaciones

En el caso de la R2P, el sistema de alerta rápida incide en la prevención de aquellos crímenes que signifiquen violaciones masivas a los derechos humanos: crímenes de guerra, crímenes contra la humanidad, genocidio y limpieza étnica.Véase párrafo 138 del documento de la ONU 2005 World summit outcome. a los derechos humanos y los movimientos de refugiados" (ONU, 2004, p. 19).

Los conflictos armados se convierten entonces en la principal causa del éxodo de personas, los cuales se han incrementado significativamente desde finales de 1946 hasta la fecha (véase gráfica 1).

Los valores de la gráfica 1 muestran que, en efecto, desde el año 1946 los conflictos se incrementaron de modo paulatino. En la actualidad existen 32 conflictos armados en el mundo, siendo que en 1946 era 18. Así mismo, en el periodo 1991-1995 el número registrado fue el mayor de toda la historia: 52 conflictos. Esta cifra se debe, principalmente, a las guerras de independencia de la antigua Yugoslavia y de Irak en esos años.

Los datos demuestran que las regiones con mayor número de conflictos en los últimos veinte años son África y Asia y es de estos territorios que provienen la mayor cantidad de refugiados en el mundo. La gráfica 2 reporta los países que originaron mayor flujo de refugiados hasta la mitad del 2014 y que pertenecen, en su mayoría a África y Asia.

Según la gráfica 2, la mayor cantidad de refugiados proviene de Siria, debido a la guerra civil que se inició con la Primavera Árabe en 2011 y a la violencia generada por el Isis. En segundo lugar se localiza Afganistán que por más de tres décadas fue el país de origen de donde procedían la mayor cifra de refugiados, alcanzado su ápice entre 1990 y 1991 con más de seis millones de refugiados (Acnur, 2014). En tercer lugar se encuentra Somalia, todavía afectada por los conflictos tribales por la lucha de poder que comenzó en 1991.

Para escapar del conflicto y la persecución, las poblaciones se ven obligadas a buscar refugio en otros países, muchas veces, vecinos. Los Gobiernos de estas naciones de destino permiten que los refugiados se asienten en campos fronterizos hasta que se consiga su traslado a las ciudades, lo cual no siempre es posible. La gráfica 3 muestra los países que acogieron al mayor número de refugiados hasta la mitad del 2014. 


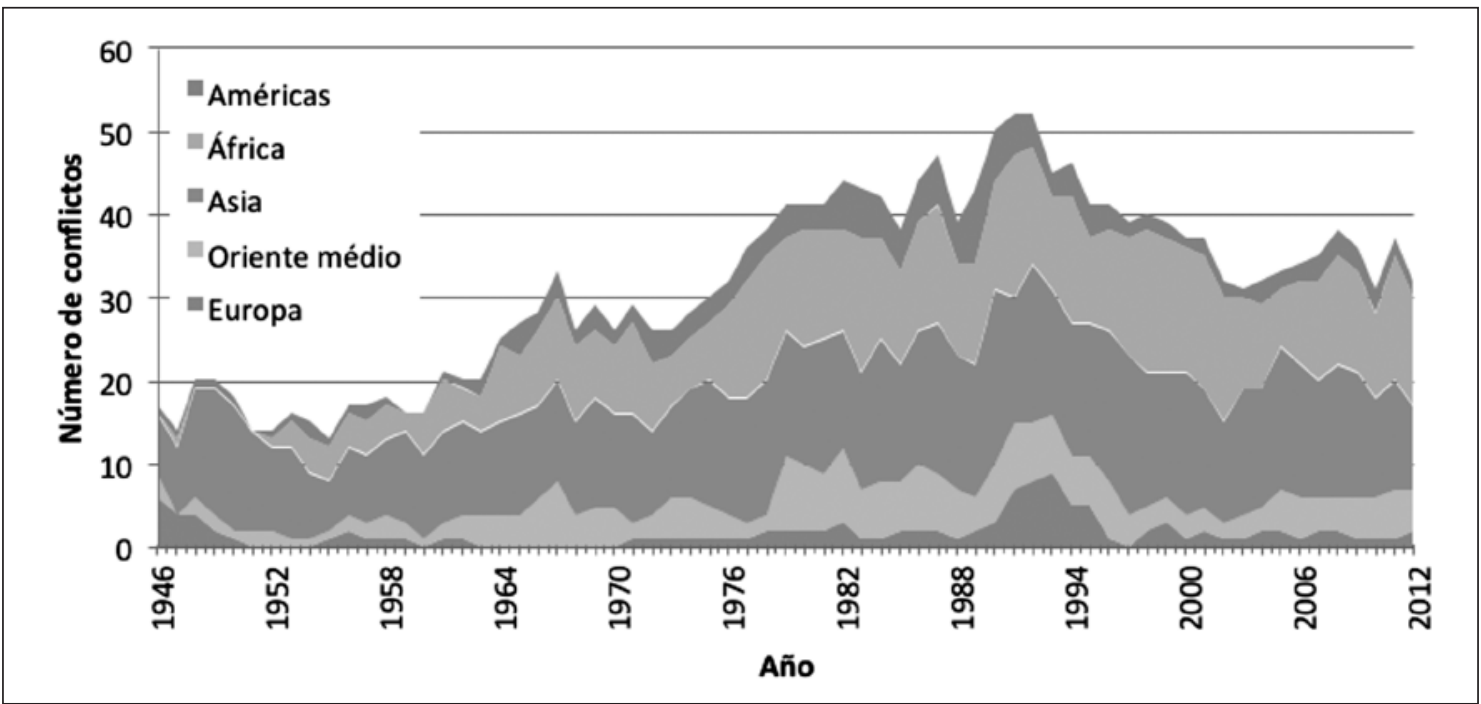

Gráfica 1. Número de conflictos por región geográfica y por año desde 1946 hasta 2012

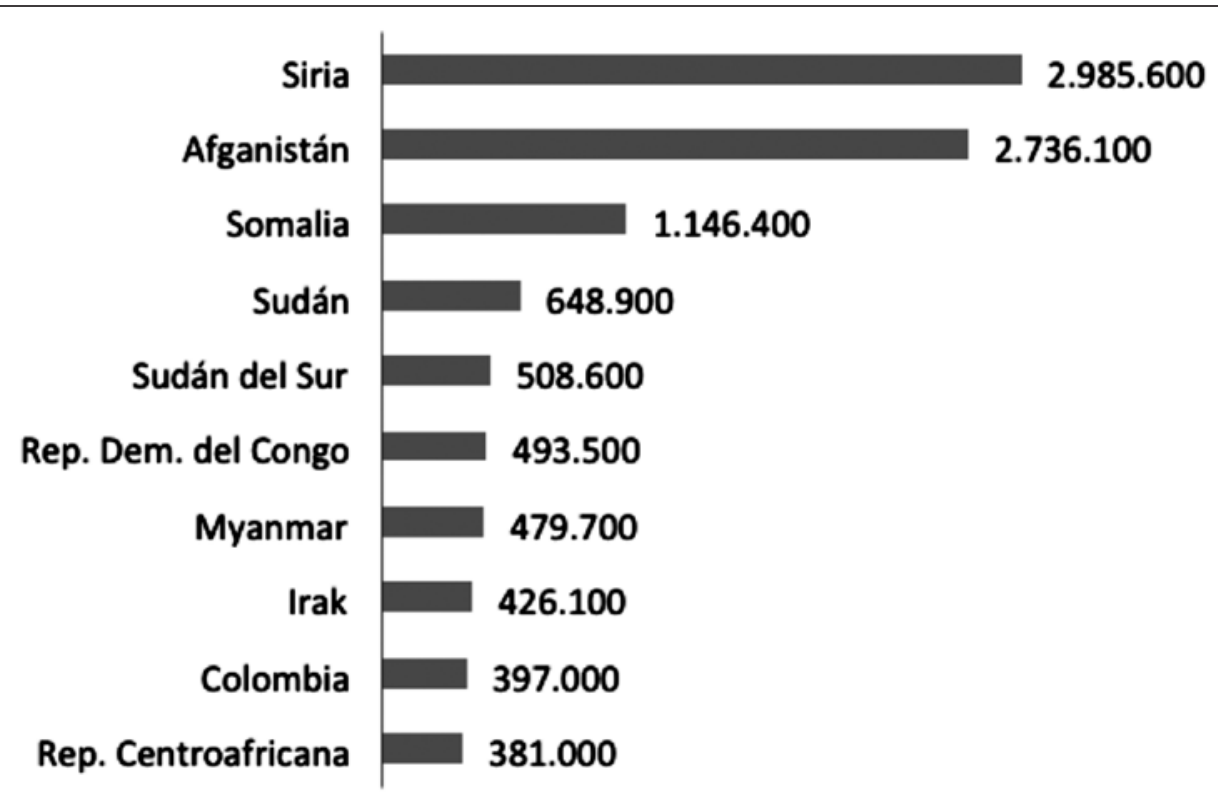

Gráfica 2. Principales países de origen de los refugiados, mitad de 2014

Fuente: Acnur (2014) 


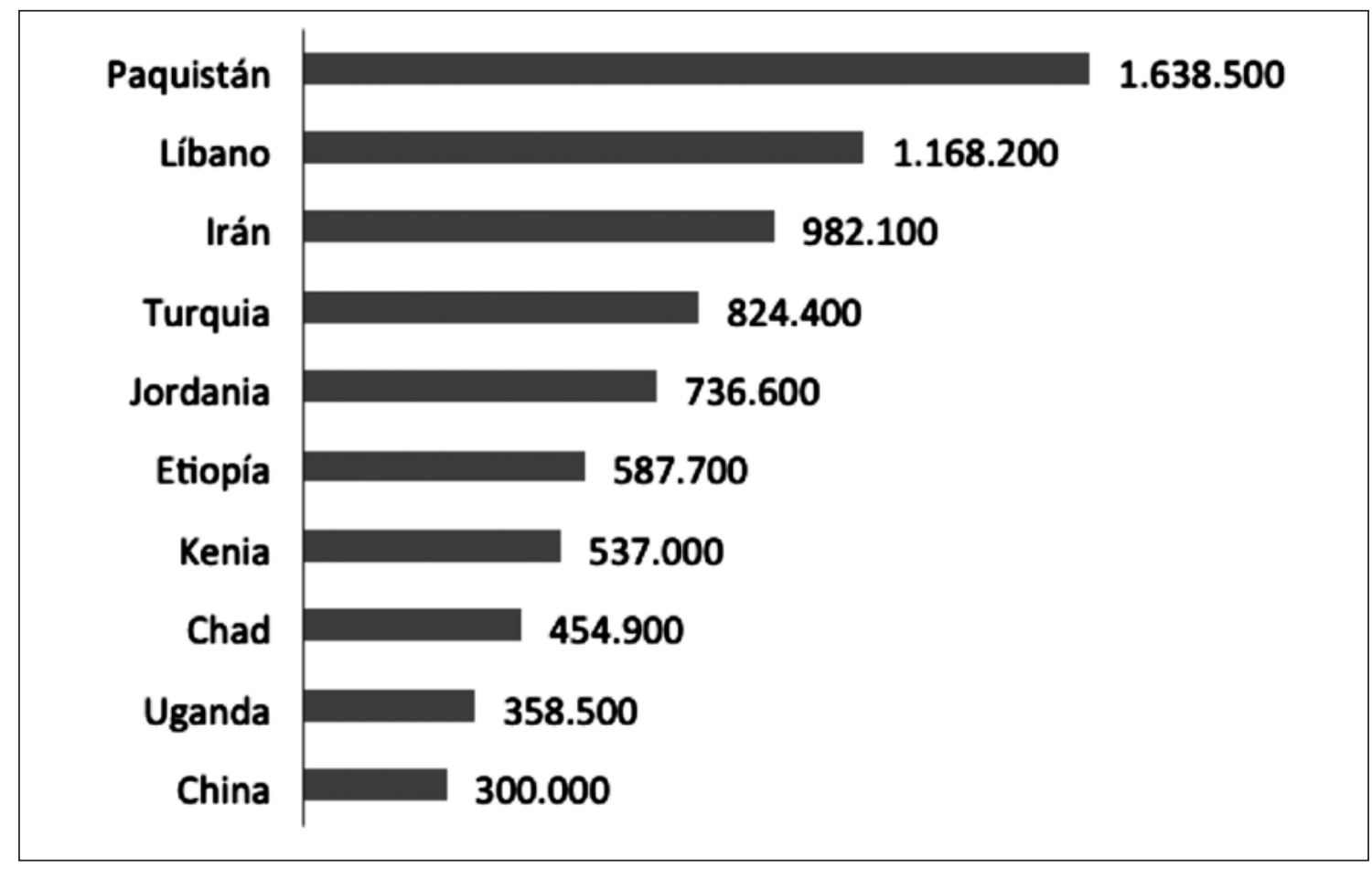

Gráfica 3. Países de destino de los refugiados

Fuente: Acnur (2014)

Pakistán sigue siendo el primer país de acogida debido a la gran cantidad de refugiados afganos. Le sigue Líbano, quien hasta hace dos años no aparecía en la lista, pero sufrió un incremento de refugiados por la crisis siria. En el caso de Colombia vale resaltar que no aparece ningún país sudamericano en la lista, dadas las múltiples fronteras que posee Colombia, ofreciendo un abanico de escape para los refugiados.

La gráfica 3 también muestra que ningún país occidental representa un destino importante para los refugiados. Ello es debido a que, como ya se indicó, los migrantes prefieren países vecinos o de la región por la facilidad de locomoción que representan. Las trabas legales que imponen los países industrializados al pedido de refugio no se sustentan por el número que puedan acoger, sino en la percepción que tiene el Gobierno de los refugiados como los otros.
Además, dentro de la R2P está considerada la reconstrucción del país, de acuerdo con el segundo pilar de la misma. Es en esta fase que el regreso de los refugiados a la nación de origen constituye un desafío importante. Los flujos de refugiados que regresan después del conflicto suponen grandes esfuerzos para sectores públicos tales como educación y prestación de servicios médicos, así como mayor competencia en el campo laboral o disputas por tierras fértiles (Zaum, 2011). Como apunta la International Commission on Intervention and State Sovereignty (ICISS) el trato desigual en el suministro de servicios básicos, asistencia para conseguir empleo y leyes sobre la propiedad privada, son una poderosa señal de que aquellos que regresan no son bienvenidos (ICISS, 2001).

En el caso de la propiedad privada se pueden presentar varios problemas, pues lo ideal sería la restitución de los bienes a quienes regresan. 
Sin embargo, estos pueden haber sido ocupados por desplazados internos, por lo que las tensiones entre dos grupos sociales pueden desestabilizar al país. Para ello, la comunidad internacional necesita trabajar en forma conjunta con la nación de origen para que las condiciones sean favorables para aquellos que desean regresar a su patria. De esta manera, no se encontrarían con hostilidades por parte de aquellas personas que se quedaron, ni serían incomodados por constituir alguna minoría étnica que pueda desencadenar nuevos conflictos internos.

Otra dificultad que asola a los refugiados una vez termina el conflicto es la de la representación política. Zaum (2011) coloca de ejemplo la guerra de los Balcanes en la década de 1990, donde los refugiados no estuvieron representados en las conferencias de Dayton en 1995, o los refugiados serbios en Kosovo quienes no tuvieron vOz ni voto en las negociaciones para decidir el estatus de Kosovo después de 2005. En el caso de estos últimos,

[...] su única representación era el gobierno serbio, cuyos intereses durante las negociaciones no eran necesariamente congruentes con los de los desplazados serbios y cuyo financiamiento a instituciones paralelas en Kosovo desalentaron la integración de los desplazados serbios en la sociedad kosovar (Zaum, 2011, p. 291).

De esta manera, los refugiados son excluidos de las negociaciones que tratan temas cardinales para el desarrollo de su vida económica, social y política. El hecho de no escuchar sus opiniones en asuntos que los implican puede desembocar en posteriores tensiones con la población local. Además, los refugiados también pueden ayudar a la reconstrucción económica del país a través de las remesas. Estas remesas muchas veces son la mayor fuente de ingresos de un Estado que se halla en reconstrucción después de un conflicto (Zaum, 2011).

Por tanto, los refugiados no son agentes pasivos sino activos en el proceso de reconstrucción del país, siendo parte significativa de las labores de la R2P. Es por ello que la reconstrucción de la nación debe ser ejecutada con la coordinación del Estado y la comunidad internacional en sintonía con los pilares de la R2P.

\section{Conclusiones}

El derecho de los refugiados ha sufrido cambios drásticos en los últimos años. La percepción que tienen de ellos los países industrializados como amenazas a su nación, junto con la guerra al terror llevada a cabo desde el 2001, no incita a pensar en una mejora de esta perspectiva.

Las políticas puestas en marcha para contener el flujo de migrantes, aún en contra de la Convención, tienen como efecto directo el empeoramiento en la calidad de vida de los solicitantes de refugio. Así mismo, políticas que buscan cerrar las fronteras a los solicitantes de refugio no son una solución duradera, ya que los migrantes van a encontrar otros medios de ingresar al país, generando un círculo vicioso de su percepción como criminales por parte de los Gobiernos de los Estados de destino.

La política del tercer país seguro no representa una solución duradera para el problema de los refugiados, pues estos terceros destinos pueden no ser capaces de garantizar los derechos que tienen los refugiados.

Es imprescindible que la comunidad internacional actúe para poner fin a las causas que obligan a las personas a huir de su patria. Así ellas no necesitarán más migrar y sus derechos humanos ya no serán más violados.

Para efectuar esta movilización general, es necesaria la coordinación de todos los agentes involucrados, ya sea el Estado de origen, Estados vecinos, agencias internacionales como el Acnur y hasta la misma ONU. Hay veces en que no se puede contar con la participación del Estado de origen, pues él mismo puede estar obligando la migración de su población a través del RID. 
Esta coordinación internacional requiere no sobrepasar sus objetivos, de modo que la solución sea peor que el problema. Para formular esta coordinación está presente la R2P que funcionaría como una especie de "manual del usuario".

La R2P pertenece al sistema de la ONU, por lo que no se precisa de nuevos debates o tratados para ponerla en funcionamiento. De este modo, se conseguiría evitar o parar las violaciones a los derechos humanos, asegurar un retorno seguro a los refugiados y mejorar la calidad de vida de la población que se quedó.

\section{Referencias}

Alborzi, M. (2006). Evaluating the effectiveness of international refugee law: the protection of iraqi refugees. Boston: Martinus Nijhoff Publishers.

Alto Comisionado de las Naciones Unidas para los Refugiados. (2006a). La situación de los refugiados en el mundo: desplazamientos humanos en el nuevo milenio. Icaria Editorial.

Alto Comisionado de las Naciones Unidas para los Refugiados. (2006b). Statement by Ms E. Feller, Assistant High Commissioner for Protection. Disponible en: http:// www.unhcr.org/cgi-bin/texis/vtx/home/ opendocPDFViewer.html?docid $=4524$ bc952\&query $=$ Handbook\%20on $\% 20$ Voluntary\%20Repatriation:\%20International\%20Protection

Alto Comisionado de las Naciones Unidas para los Refugiados. (2014). Mid-year trends 2014. Disponible en: http://www.acnur.org/ t3/fileadmin/scripts/doc.php?file $=$ t3/fileadmin/Documentos/Estadisticas/2014/9985

Alto Comisionado de las Naciones Unidas para los Refugiados. (2015). Acnur pide acción urgente ante nueva tragedia en el Mediterráneo. Disponible en: http://www. acnur.org/t3/noticias/noticia/acnur-pideaccion-urgente-ante-nueva-tragedia-enel-mediterraneo/
Betts, A., Loescher, G. \& Milner, J. (2012). The United Nations High Commissioner for Refugees (UNHCR): the politics and practice of refugee protection (global institutions). Oxford: Routledge.

Carlier, J., Vanheule, D., Peña, C. \& Hullman, K. (1997). Who is a refugee? A comparative case law study. La Haya: Kluwer Law International.

Clark, T. \& Simeon, J. (2014). UNHCR international protection policies 2000-2013: from cross-road to gaps and responses. Refugee Survey Quarterly, 33(3), pp. 1-33.

Convención sobre el Estatuto de los Refugiados. (1951). 28 de julio.

Dauvergne, C. (2008). Making people illegal: what globalization means for migration and law. Cambridge: Cambridge University Press.

Co-Chair's Statement (2011). Fourth Bali Regional Ministerial Conference on people smuggling, trafficking in persons and related transnational crime. Disponible en: http://www.unodc.org/documents/ southeastasiaandpacific/2011/04/somindonesia/110330_FINAL_Ministerial_Cochairs_statement_BRMC_IV.pdf

Declaración de Tlatelolco sobre Acciones Prácticas en el Derecho de los Refugiados en América Latina y el Caribe. (1999). 11 de mayo.

Foster, M. (2007). International refugee law and socio-economic rights: refuge from deprivation. Cambridge: Cambridge University Press.

Foster, M. (2012). The implications of the failed Malaysian solution: the Australian high court and responsibility sharing at international law. Melbourne Journal of International Law, 13(1), pp. 395-423.

Hathaway, J. (1990). A reconsideration of the underlying premise of refugee law. Harvard International Law Journal, 31(1), pp. 129-183. 
Hathaway, J. (1991). The law of refugee status. Toronto: Butterworths.

Hathaway, J. (1998). Can international refugee law be made relevant again? Law Quadrangle Notes, 41(3), pp. 106-108.

Hathaway, J. (2007). Why refugee law still matters. Melbourne Journal of International Law, 8(1), pp. 89-103.

International Commission on Intervention and State Sovereignty. (2001). The responsibility to protect: report of the International Commission on Intervention and State Sovereignty. Ottawa: International Development Research Centre.

James, P. (2014). Faces of globalization and the borders of states: from asylum seekers to citizens. Citizenship Studies, 18(2), pp. 208-223.

Kelley, N. (2007). International refugee protection challenges and opportunities. International Journal of Refugee Law, 19(3), pp. 401-439.

Kneebone, S. (2009). Introduction: refugees and asylum seekers in the international context. Rights and realities. En: S. Kneebone (ed.). Refugees, asylum seekers and the rule of law: comparative perspectives (pp. 1-31). Cambridge: Cambridge University Press.

Kneebone, S. (2014). The Bali process and global refugee policy in the Asia-Pacific region. Journal of Refugee Studies, 27(4), pp. 596-618.

Millbank, A. (2000). The problem with the 1951 Refugee Convention. Research Paper, 5. Disponible en: http://www.aph.gov. au/About_Parliament/Parliamentary_Departments/Parliamentary_Library/pubs/rp/ rp0001/01RP05

Orchard, P. (2010). The perils of humanitarian: refugee and IDP protection in situations of regime-induced displacement. Refugee Survey Quarterly, 29(1), pp. 38-60.

Organización de las Naciones Unidas. (2001). Asamblea General. Resolución 60/1: World Summit Outcome. Disponible en: http:// www.un.org/summit2005/documents.html

Organización de las Naciones Unidas. (2004). Direitos humanos e refugiados. Ficha Informativa, 20.

Organización de las Naciones Unidas. (2009). Asamblea General. Resolución 63/677: hacer efectiva la responsabilidad de proteger. Disponible en: http://www.un.org/ es/comun/docs/?symbol=A/63/677

Protocolo sobre el Estatuto de los Refugiados. (1967). 31 de enero.

Saltman, E. \& Winter, C. (2014). Islamic State: the changing face of modern jihadism. Disponible en: http://www.quilliamfoundation. org/wp/wp-content/uploads/publications/ free/islamic-state-the-changing-face-ofmodern-jihadism.pdf

Türk, V. (2013). The UNHCR's role in supervising international protection standards in the context of its mandate. En: J. Simeon (ed.). The UNHCR and the supervision of international refugee law (pp. 39-58). Cambridge: Cambrigde University Press.

Universidad de Upsala. (s. f.). UCDP/PRIO armed conflict dataset. Disponible en: http:// www.pcr.uu.se/research/ucdp/datasets/ ucdp_prio_armed_conflict_dataset/

Western, J. \& Goldstein, J. (2011). Humanitarian intervention comes of age: lessons from Somalia to Libya. Foreign Affairs, 90(6), pp. 48-59.

Zaum, D. (2011). Post-conflict Statebuilding and forced migration. En: A. Betts \& G. Loescher (eds.). Refugees in international relations (pp. 285-304). Oxford: Oxford University Press. 